\title{
Oral Nifidepine versus IV labetalol in severe preeclampsia: A randomized control trial
}

\author{
Tayyiba Wasim ${ }^{1}$, Shazia Agha², \\ Kanwal Saeed ${ }^{3}$, Anam Riaz ${ }^{4}$
}

\begin{abstract}
Objective: To compare oral Nifidepine and IV labetalol in terms of rapidity of BP control in severe preeclampsia.

Methods: All patients coming to Services Hospital from March 2017 to February 2019 with diagnosis of severe preeclampsia $\geq 24$ weeks gestation were randomized to either receive Nifidepine or Labetalol. Primary outcome measure was time taken to control BP and number of doses required. Secondary outcome measures were side effects of drugs, APGAR score, NICU admission and perinatal mortality.

Results: Two hundred four patients were included in trial with 102 patients in each group. Labetalol took $22.6 \pm 13.5$ minutes and Nifidepine took $22.09 \pm 11.7$ minutes to achieve target BP $(p>0.05)$. Labetalol required $2.3 \pm 1.58$ doses and Nifidepine $2.2 \pm 1.58$ doses to control BP $(p>0.05)$. No maternal side effects were seen in $86(84.31 \%)$ and $92(90.19 \%)$ patients in both groups $(p>0.05)$. Mean gestational age at birth was 34.8 \pm 2.73 weeks in Labetalol and 35.2 \pm 2.48 weeks in Nifidepine group ( $>0.05)$. In labetalol group, $43(42.15 \%)$ babies had APGAR Score $<7 / 10$ and 23(22.54\%) babies required admission to NICU while in Nifidepine group 42 (41.17\%) babies had Apgar score < 7/10\& 30(29.4\%) babies were admitted to NICU(p>0.05). There were 21(20.5\%) perinatal deaths in labetalol Group-And 19(18.6\%) in Nifidepine group ( $\mathrm{p}>0.05)$

Conclusion: Oral Nifidepine and IV labetalol are equally efficacious in controlling BP in patients with severe pre eclampsia without any significant side effects.
\end{abstract}

KEYWORDS: Severe preeclampsia, Labetalol, Nifidepine.

doi: https://doi.org/10.12669/pjms.36.6.2591

How to cite this:

Wasim T, Agha S, Saeed K, Riaz A. Oral Nifidepine versus IV labetalol in severe preeclampsia: A randomized control trial. Pak J Med Sci. 2020;36(6):1147-1152. doi: https://doi.org/10.12669/pjms.36.6.2591

This is an Open Access article distributed under the terms of the Creative Commons Attribution License (http://creativecommons.org/licenses/by/3.0), which permits unrestricted use, distribution, and reproduction in any medium, provided the original work is properly cited.

\section{INTRODUCTION}

1. Dr. Tayyiba Wasim, FCPS

2. Dr. Shazia Agha, FCPS,

3. Dr. Kanwal Saeed, FCPS-I,

4. Dr. Anam Riaz, FCPS-I

1-4: Department of Gynecology,

Services Institute of Medical Sciences,

Lahore, Pakistan.

Correspondence:

Dr, Tayyiba Wasim

Professor Gynae Unit II,

Services Institute of Medical Sciences.

133 A PCSIR Housing Society,

Canal Bank,

Lahore, Pakistan.

E-mail: tayyibawasim@yahoo.com

* Received for Publication:

March 26, 2020

* Accepted for Publication:

July 5, 2020
Hypertensive disorders of pregnancy complicate $4-7 \%$ of pregnancies and the second leading cause of maternal death worldwide ${ }^{1}$. The disease varies in spectrum from mild hypertension to preeclampsia and eclampsia. Severe preeclampsia is defined as systolic blood pressure (BP) of $\geq 160 \mathrm{mmh}$ and diastolic BP of $\geq$ $110 \mathrm{mmHg}$ along with proteinuria of $\geq 300 \mathrm{mg} / 24$ hours. In addition, clinical symptoms and signs of headache, visual disturbances, epigastric pain, abnormal liver and renal function tests and thrombocytopenia may be present. If not treated, it results in pulmonary edema, cerebral hemorrhage, liver and renal failure and ultimately 
maternal death. As a result of placental hypo perfusion, fetal growth restriction and death may occur as well. ${ }^{2}$

The only effective treatment of severe preeclampsia is delivery of the fetus but immediate antihypertensive treatment is given to stabilize the patient and prevent further complications. Intravenous drugs in the form of labetalol and hydralazine have been traditionally used as first line drugs for control of severe hypertension in pregnancy. Although adverse effects of drugs have been reported but both are effective in controlling BP in severe pre eclampsia. Nifidepine is a calcium channel blocker with advantages of oral administration. Worldwide trials comparing Nifidepine, hydralazine and labetalol in hypertensive emergency have been conducted with variable results regarding their efficacy in controlling BP and fetal effects. ${ }^{3-5}$ Duley et al in Cochrane data base review reported lack of evidence regarding choice of antihypertensive. ${ }^{6}$ Recent systematic review has declared all three drugs equally effective in controlling $\mathrm{BP}$ in hypertensive emergencies in pregnant women. ${ }^{7}$ NICE guidelines recommend Labetalol, hydralazine and Nifidepine as first line antihypertensive in severe pre eclampsia. ${ }^{8}$

Pakistan has high burden of hypertensive disease in pregnancy. Eclampsia is second major cause of maternal death and claims 2000 maternal lives per year. ${ }^{9}$ IV hydralazine and labetalol are used for severe pre eclampsia in Pakistan depending on their availability. Nifidepine can be a good alternative in our set up, as it is cheap and can be given orally in rural settings of basic health units and tehsil head quarter hospitals. No trial comparing IV labetalol and Nifidepine has been reported from Pakistan. There are no guidelines for management of preeclampsia in Pakistan. We planned this trial with the aim to compare oral nifedipine with IV labetalol for BP control so that recommendations for choice of drugs in severe hypertension can be made.

\section{METHODS}

This open label randomized control study was conducted in the Department of Obstetrics \& Gynecology, Services Institute of Medical Sciences, Services Hospital Lahore from March 2017 to February 2019. Services Hospital Lahore is a tertiary care hospital attached to public sector medical college, catering the needs of a large population. Ethical approval for the study was taken by the Institutional Review Board (IRB) SIMS, Services Hospital Lahore on February 16, 2017 number IRB/2017/306/SIMS and Trial Registration no: NCT03325348.

All pregnant patients' $\geq 28$ weeks of gestation diagnosed with severe pre eclampsia as defined by systolic BP of $\geq 160 \mathrm{mmHg}$ or diastolic BP of $\geq 110 \mathrm{mmHg}$ with proteinuria and alive baby were admitted and offered to enrol in the trial after written informed consent. Women with history of chronic hypertension without proteinuria, with heart rhythm abnormalities, asthma, anomalous baby and intrauterine death were excluded from the trial. Detailed history regarding booking, drugs for hypertension, symptoms of headache, blurring of vision, dizziness and epigastric pain was taken. Their relevant investigations of blood group, complete blood count, urine complete examination, serum uric acid, liver function tests, clotting profile were sent. Ultrasound was done to see fetal wellbeing and biometry along with liquor volume. The patients were randomized to two groups based on computer generated random numbers, 102 patients in each Group-After sample sizecalculation. The patients in Group-A were given intravenous labetalol injection (in an escalating dose regimen of 20,40,80,80 and $80 \mathrm{mg}$ ) and a mint tablet every 15 minutes. Patients in Group-B were given Nifidepine (10mg tablet, orally every 15 minutes up to five doses) and intravenous placebo saline injection. BP was recorded every 15 minutes until the target blood pressure of $\leq 150 / 100 \mathrm{mmHg}$ was achieved. Fetal heart rate monitoring was done every 15 minutes throughout administration. If $\mathrm{BP}$ was not controlled in one hour, other antihypertensive drugs were given. Similarly, after successful BP control, routine antihypertensive therapy was started two hours after last study drug administration. Corticosteroid injection were given for lung maturity to all participants less than 36 weeks duration. Depending on fetus and maternal condition, delivery was planned according to gestational age and bishop score.

Primary outcome measure was time taken to control the BP and number of doses of drugs required. Secondary outcome measure were maternal complications of placental abruption, HELLP and eclampsia. Neonatal outcome was measured in form of Apgar score at five minutes, admission to NICU and perinatal death. Side effects of both drugs were also noted. Data was entered and analyzed using SPSS version 23. The comparison between qualitative variables was done by using chi 
square test or fisher Exact test where appropriate. All P-values were two tailed and p-value of 0.05 or less was considered significant.

Sample Size: Sample size was calculated by using WHO statistical software (S.size). Assumption for sample size estimation was the hypothesis test for difference of two proportions (two sided test). The estimated sample size is sufficient to detect the difference of $20 \%$ among the two groups at significance level $5 \%$ and power of study $90 \%$. The estimated sample size was 102 for each group.

\section{RESULTS}

Total 204 patients were recruited in this randomized controlled study. Group-A with 102 patients was given IV labetalol and Group-B with 102 patients was given oral Nifidepine. Patient characteristics are shown in Table-I. Age of patients was $28.1 \pm 4.37$ years and $24.6 \pm 4.65$ in both groups respectively while $71(69.6 \%)$ and $62(60.78 \%)$ in each group were primigravida $(\mathrm{p}=0.217)$. In Group-A, 66(64.70\%) patients were booked and in Group-B 70(68.62\%) patients were booked ( $\mathrm{p}>0.05)$.

Regarding primary outcome of the study, that is time taken to achieve blood pressure control as shown in Table-II, average time taken was $22.69 \pm 13.5$ minutes in Group-A \& 22.09 \pm 11.7 minutes in Group-B $(p=0.110)$. Mean doses required in each group were $2.36 \pm 1.58$ doses in Group-A and 2.28 \pm 1.58 doses in Group-B ( $\mathrm{p}=0.183$ ). All patients had their BP controlled in one hour. No maternal side effects were seen in $86(84.31 \%)$ patients of Group-A and $92(90.19 \%)$ patients in Group-B $(p=0.521)$. No maternal complications were seen in $93(91.17 \%)$ and $91(89.2 \%)$ of patients in both groups respectively $(\mathrm{p}=0.561)$. Eclampsia and placental abruption was seen in $4(3.92 \%)$ patients each in Labetalol Group-A and 03 patients developed eclampsia and 7(6.86\%) patients had placental abruption in Group-B.

Mean gestational age at birth was $34.8 \pm 2.73$ weeks in Group-A and $35.2 \pm 2.48$ weeks in Group-B $(p=0.292)$ with mean birth weight of babies $2.2 \pm 0.41 \mathrm{~kg}$ and $2.3 \pm 0.38 \mathrm{~kg}$ respectively in Group-A and B. In Labetalol Group, 43 (42.15\%) babies had APGAR Score < 7/10 and 23(22.54\%) babies required admission to NICU. In Nifidepine group $42(41.17 \%)$ babies had Apgar score $<7 / 10 \&$ $30(29.4 \%)$ babies were admitted to NICU ( $>>0.05$ ). There were $81(79.5 \%)$ live births, $3(2.9 \%)$ still births \& $18(17.6 \%)$ early neonatal deaths while in Nifidepine group, there were $83(81.3 \%)$ live births, 5(4.9\%) still births \& $14(13.7 \%)$ neonatal deaths $(\mathrm{p}=0.328)$.

\section{DISCUSSION}

Mean age of our patients was comparable in both groups ( $28.1 \pm 4.37$ years and $24.6 \pm 4.65$ years ( $p>0.05$ ). $69.6 \%$ and $60.7 \%$ patients in both groups were primigravida, as is the case worldwide that majority are primigravida. ${ }^{3-7}$

In our study, labetalol and Nifidepine were found to be equally effective in controlling BP in pregnant women with severe preeclampsia taking mean time of $22.69 \pm 13.5$ and $22.09 \pm 11.7$ minutes each $(p>0.05)$. Number of doses required were not statistically different in both groups as mean dose to control BP was $2.36 \pm 1.5$ doses in labetalol GroupAnd 2.28 \pm 1.58 doses in Nifidepine group ( $p>0.05)$. Similar trials conducted by Raheem et al, Shekhar et al, Anjuman et al and Yogita et al showed that

Table-I: Maternal characteristics.

\begin{tabular}{|c|c|c|c|c|}
\hline \multicolumn{2}{|c|}{ Maternal Characteristics } & Group-A Labetalol $(n=102)$ & Group-B Nifidepine $(n=102)$ & $P$ value \\
\hline \multicolumn{2}{|c|}{ Maternal Age(years) Mean } & $28.15 \pm 4.372$ & $24.65 \pm 4.652$ & 0.217 \\
\hline \multicolumn{2}{|l|}{ Primigravida } & $71(69.60 \%)$ & $62(60.78 \%)$ & 0.186 \\
\hline \multicolumn{2}{|l|}{ Multigravida } & $31(30.39 \%)$ & $40(39.21 \%)$ & 0.186 \\
\hline \multirow{3}{*}{$\begin{array}{l}\text { Socioeconomic } \\
\text { Status }\end{array}$} & Poor & $24(23.52 \%)$ & $31(30.39 \%)$ & \multirow{3}{*}{0.342} \\
\hline & Middle & $55(53.92 \%)$ & $55(53.92 \%)$ & \\
\hline & High & $23(22.54 \%)$ & $16(15.68 \%)$ & \\
\hline \multicolumn{2}{|c|}{ Gestational age Weeks } & $34.83 \pm 2.736$ & $35.26 \pm 2.485$ & \multirow[t]{2}{*}{0.292} \\
\hline \multirow[b]{2}{*}{ Booking status } & Booked & $66(64.70 \%)$ & $70(68.62 \%)$ & \\
\hline & Unbooked & $36(35.29 \%)$ & $32(31.37 \%)$ & 0.552 \\
\hline
\end{tabular}

Pak J Med Sci September - October 2020 Vol. 36 No. 6 www.pjms.org.pk 1149 
Table-II: Fetomaternal Outcome.

\begin{tabular}{|c|c|c|c|c|}
\hline \multicolumn{2}{|l|}{ Fetomaternal OUTCOME } & $\begin{array}{l}\text { Group-A } \\
\text { Labetalol }\end{array}$ & $\begin{array}{l}\text { Group-B } \\
\text { Nifidepine }\end{array}$ & P value \\
\hline \multicolumn{2}{|c|}{ Time (minutes) taken to achieve blood pressure Mean } & $22.69 \pm 13.57$ & $22.09 \pm 11.74$ & 0.110 \\
\hline \multicolumn{2}{|c|}{ Total antihypertensive doses to achieve blood pressure Mean } & $2.36 \pm 1.581$ & $2.28 \pm 1.581$ & 0.183 \\
\hline \multirow{2}{*}{ Mode of delivery } & Vaginal & $44(43.13 \%)$ & $49(48.03 \%)$ & \multirow{2}{*}{0.482} \\
\hline & Caesarean & $58(56.86 \%)$ & $53(51.96 \%)$ & \\
\hline \multicolumn{2}{|l|}{ Birth Weight $(\mathrm{kg})$ Mean } & $2.28 \pm 0.411$ & $2.38 \pm 0.389$ & 0.182 \\
\hline \multirow{2}{*}{ Gender of Baby } & Male & $62(60.78 \%)$ & $49(48.03 \%)$ & \multirow{2}{*}{0.068} \\
\hline & Female & $40(39.21 \%)$ & $53(51.96 \%)$ & \\
\hline \multirow{2}{*}{ NICU admission } & Yes & $23(22.54 \%)$ & $30(29.41 \%)$ & \multirow{2}{*}{0.264} \\
\hline & No & $79(77.45 \%)$ & $72(70.58 \%)$ & \\
\hline \multirow{2}{*}{ APGAR score } & $<7 / 10$ & $43(42.15 \%)$ & $42(41.17 \%)$ & \multirow{2}{*}{0.887} \\
\hline & $>7 / 10$ & $59(57.84 \%)$ & $60(58.82 \%)$ & \\
\hline \multirow{3}{*}{ Neonatal Outcome } & Live Births & $81(79.41 \%)$ & $83(81.37 \%)$ & \multirow{3}{*}{0.328} \\
\hline & Stillbirths & $03(2.95 \%)$ & $05(4.9 \%)$ & \\
\hline & Neonatal Death & $18(17.64 \%)$ & $14(13.72 \%)$ & \\
\hline \multirow{5}{*}{ Maternal Side effects } & No side effects & $86(84.31 \%)$ & $92(90.19 \%)$ & \multirow{5}{*}{0.521} \\
\hline & Palpitation & $10(9.80 \%)$ & $8(7.84 \%)$ & \\
\hline & Headache & $4(3.92 \%)$ & $1(0.98 \%)$ & \\
\hline & Dizziness & $1(0.98 \%)$ & 0 & \\
\hline & Hypotension & $1(0.98 \%)$ & $1(0.98 \%)$ & \\
\hline \multirow{5}{*}{ Maternal Complications } & No complication & $93(91.17 \%)$ & $91(89.21 \%)$ & \multirow{5}{*}{0.561} \\
\hline & Eclampsia & $4(3.92 \%)$ & $3(2.94 \%)$ & \\
\hline & Placental Abruption & $4(3.92 \%)$ & $7(6.86 \%)$ & \\
\hline & HELLP & 0 & $1(0.98 \%)$ & \\
\hline & DIC & $1(0.98 \%)$ & 0 & \\
\hline
\end{tabular}

BP control was controlled significantly earlier in patients who were given Nifedipine as compared to labetalol and they required less number of doses.,10-12 Lakhshami et al declared labetalol superior regarding earlier control of BP while Shi DD et al reported both achieved BP control at same time with two doses in both groups. ${ }^{13,14}$ The difference results in various trials may be related to the smaller number of participants in each group. The results of our study showing oral nifedipine equally efficacious in controlling BP in comparison to IV drug has important implications in our set up where cost, availability and administration of IV drugs is a big issue Orally used drug will have a wider use in communities, basic health units and LHVs which receive the major burden of disease.

The side effects profile of the patients was comparable and $84.3 \%$ patients of labetalol Group-And $90.1 \%$ patients in Nifidepine group did not experience any side effects $(p>0.05)$. Only few experienced palpitations, headache and hypotension which was well tolerated. Another study from Lahore comparing Nifidepine to hydralazine has also shown minimal side effects with nifedipine. ${ }^{15}$ Raheem et al and Anjuman et al reported significantly increased maternal heart rate in patients who received Nifidepine but this was not seen in our study. Shekar et al in their 


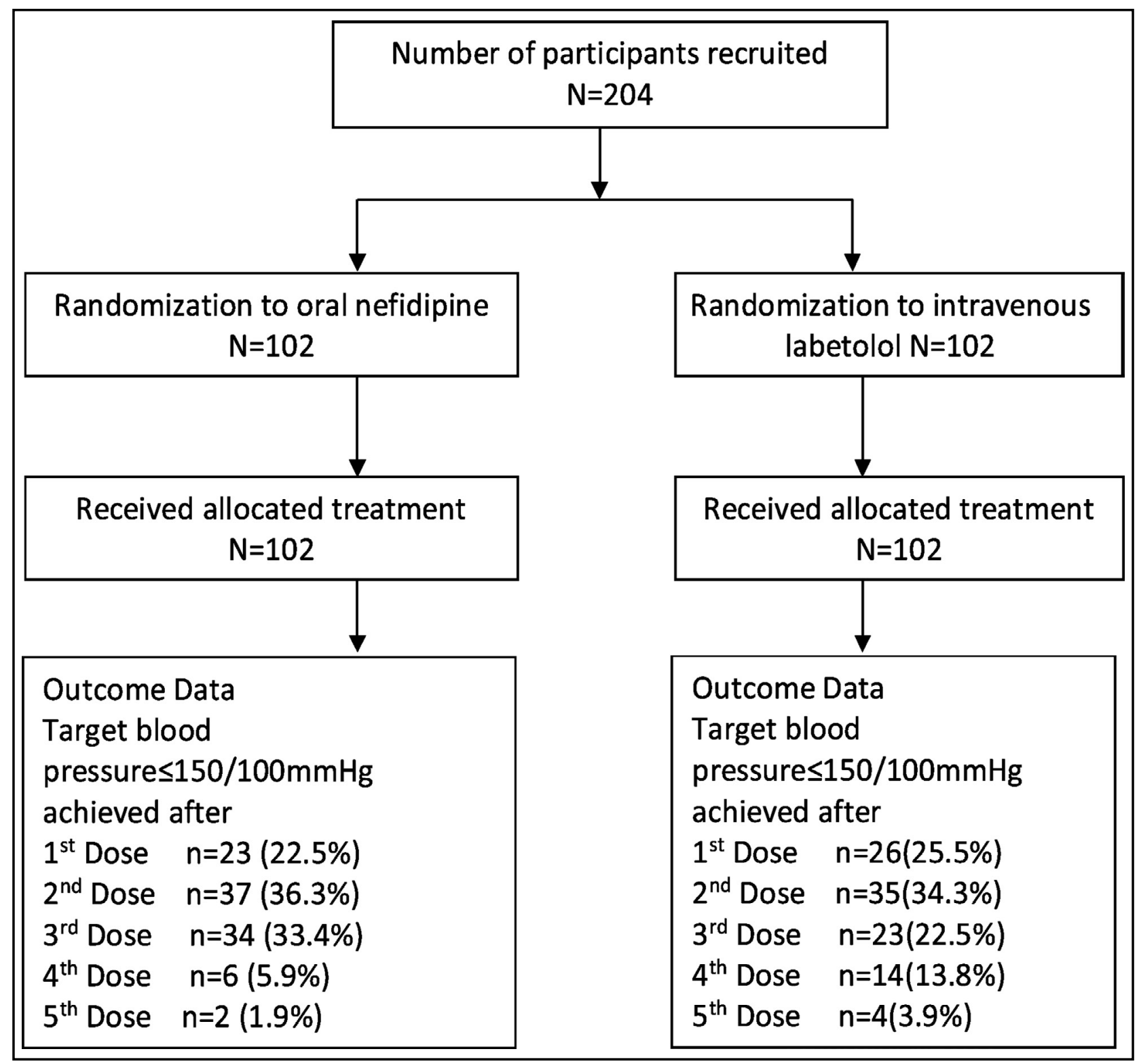

review have reported significantly reduced side effects in patients who were given nifidepine. ${ }^{16}$

In this study, average gestation was $34.8 \pm 2.73$ weeks in labetalol Group-And 35.2 \pm 2.48 weeks in patients given Nifidepine with average birth weight of $2.2 \pm 0.41 \mathrm{~kg}$ and $2.3 \pm 0.38 \mathrm{~kg}$ respectively $(p>0.05)$ This is in contrast to studies reported by Raheem et al and Yogita et al where majority babies delivered at gestational age of 37-39 weeks.,12 The reason may be that quite a lot of our patients were unbooked and were not taking any antenatal care. Regular antenatal care has key role to play in BP control and hence prolongation of pregnancy.

APGAR score $<7$ at five minutes was seen in $43.15 \%$ and $41.17 \%$ patients in labetalol and
Nifidepine groups respectively. Although more patients $(29.4 \%)$ on Nifidepine required NICU admissions as compared to $22.5 \%$ patients in labetalol Group-But it was not statistically significant $(p>0.05)$. Li QQ in meta-analysis reported better BP control with Nifidepine but no difference in APGAR score and perinatal outcome. ${ }^{16}$ Yogita et al and Anjuman et al reported significantly less number of NICU admissions in patients who were given Nifidipine. ${ }^{11,12}$ Shekar et al reported that APGAR score and NICU admissions were comparable in both groups but risk of neonatal death was decreased in patients who were given Nifidepine. ${ }^{17}$ Our study showed $21(20.5 \%)$ perinatal deaths in labetalol group 
with three stillbirths and 18 early neonatal deaths while patients in Nifidepine group had 19(18.6\%) perinatal deaths with five stillbirths and 14 early neonatal deaths which is statistically insignificant $(p>0.05)$. The reason for stillbirths was abruption and severe IUGR.

Prematurity and growth restriction have a major role in adverse perinatal outcome in this study. NICU in government hospitals is overburdened with overwhelming number of patients and poor resources lead to increased chances of early neonatal death in premature babies. Increasing burden of perinatal mortality for severe hypertension is reported from other developing countries as well. ${ }^{18}$ Perinatal mortality rates are comparable in both groups in our study. Firoz $\mathrm{T}$ in meta-analysis showed similar success in control of $\mathrm{BP}$ with both drugs but better neonatal outcome in patients receiving nifedipine. ${ }^{19}$

\section{CONCLUSION}

Oral Nifidepine and IV labetalol are equally efficacious in controlling BP in patients with severe pre eclampsia without any significant side effects. Neonatal outcome in terms of NICU admission and perinatal mortality is also comparable. Nifidepine can be recommended as first line drug for control of severe hypertension due to ease of oral administration, cost effectiveness and easy availability.

Conflict of Interest: There is no conflict of interest.

Grant Support \& Financial Disclosures: None.

\section{REFERENCES}

1. Say L, Chou D, Gemmill A, Tuncalp O, Moller AB, Daniels $\mathrm{J}$, et al. Global causes of maternal death: a WHO systematic analysis. The Lancet Global Health. 2014;2(6):e323-333. doi: 10.1016/S2214-109X(14)70227-X

2. Ahmad AS, Samuelsen SO. Hypertensive disorders in pregnancy and fetal death at different gestational lengths: A population study of 2121371 pregnancies. BJOG. 2012;119(12):1521-1528. doi: 10.1111/j.14710528.2012.03460.x

3. Khan A, Hafeez S, Nasrullah FD. Comparison of hydralazine and labetalol to lower severe hypertension in pregnancy. Pak J Med Sci. 2017;33(2):466-470. doi: 10.12669/ pjms.332.12243

4. Rezaei Z, Sharbaf FR, Pourmojieb M, Youefzadeh-Fard Y, Motevalian M, Khazaeipour Z, et al. Comparison of the efficacy of nifedipine and hydralazine in hypertensive crisis in pregnancy. Acta Medica Iranica. 2011;49(11):701-706.

5. Raheem IA, Saaid R, Omar SZ, Tan PC. Oral nifedipine versus intravenous labetalol for acute blood pressure control in hypertensive emergencies of pregnancy: A randomised trial. BJOG. 2012;119(1):78-85. doi: 10.1111/j.14710528.2011.03151.x
6. Duley L, Meher S, Jones L. Cochrane Pregnancy and Childbirth Group. Drugs for treatment of very high blood pressure during pregnancy. Cochrane Database Syst Rev. 2013;9(73):CD001449. doi: 10.1002/14651858.CD001449. pub3

7. Sridharan K, Sequeira RP. Drugs for treating severe hypertension in pregnancy: A network meta-analysis and trial sequential analysis of randomized clinical trials. Br J Clin Pharmacol. 2018;84:1906-1916. doi: 10.1111/bcp.13649

8. Hypertension in pregnancy: The management of hypertensive disorders during pregnancy. August 2010. NICE Clinical Guidelines No. 107.

9. Saving mother's lives in Pakistan. The White Ribbon Alliance; [October 10, 2013; cited 22 April 2014]; Available from: http:// whiteribbonalliance.org/?s=Saving+mother $\%$ E2\%80\%99s+lives+in+Pakistan.

10. Shekar SC, Sharma C, Thakur S, Varma S. Oral nifedipine or intravenous labetalol for hypertensive emergency in pregnancy: A randomized controlled trial. Obstet Gynecol. 2013;122(5):1057-1063. doi: 10.1097/AOG.0b013e3182a9ea68

11. Anjuman Alam, S.M.A. Zakaria. Oral nifedipine or intravenous labetalol for acute blood pressure control in hypertensive emergency in pregnancy: A randomized controlled trial. IJRCOG. 2019;8(5):1921-1927.

12. Gavit Y, Sharma D, Pratibha V. Dixit. A comparative study of oral nifedipine and intravenous labetalol in control of acute hypertension in severe pre-eclampsia and eclampsia. IJRCOG. 2018;7(2): doi: 10.18203/2320-1770.ijrcog20180201

13. Sathya Lakshmi B, Dasari P. Oral nifedipine versus intravenous labetalol in hypertensive urgencies and emergencies of pregnancy: A randomized clinical trial. Obstet Med. 2012;5(4):171-175. doi: 10.1258/om.2012.120010

14. Shi DD, Yang FZ, Zhou L, Wang N. Oral nifedipine vs. intravenous labetalol for treatment of pregnancy-induced severe pre-eclampsia. J Clin Phar Ther 2016;41(6):657-661. doi: $10.1111 /$ jcpt.12439

15. Bashir S, Cheema AA, Mazhar R, Rehman A. The Efficacy of Hydralazine and Nifedipine in the Management of Severe Pre-Eclampsia. Ann King Edw Med Uni. 2013;19(2):164-169.

16. Liu Q, Yu Y, Gong S, Huang L. Clinical efficacy and perinatal outcome of nifedipine for severe preeclampsia: metaanalysis. Zhonghua Fu Chan Ke Za Zhi. 2012;47(8):592-597.

17. ShekharS, Gupta N, Kirubakaran R, PareekP.Oral nifedipine versus intravenous labetalol for severe hypertension during pregnancy: A systematic review and meta-analysis. BJOG. 2016;123(1):40-47. doi: 10.1111/1471-0528.13463

18. Firoz T, Magee LA, Mac Donell K, Payne BA, Gordon R, Vidler M, von Dadelszen P. Oral antihypertensive therapy for severe hypertension in pregnancy and postpartum: A Syst Rev. BJOG. 2014;121(10):1210-1218. doi: 10.1111/14710528.12737

19. Dassah ET, Kusi Mensah E, Morhe ES K, Odoi AT. Maternal and perinatal outcomes among women with hypertensive disorders in pregnancy in Kumasi, Ghana. PLoS ONE 2019;14(10):1-13. doi: 10.1371/journal.pone.0223478

\section{Authors' Contribution:}

TW: Conceptualized and designed the study, reviewed the manuscript and approved the final version. She is responsible for accuracy and integrity of work.

SA: contributed to maintenance of data base and initial writing of script.

KS \& AR: did the data entry and statistical analysis. 